Fanum

Sociológico

\section{Forum Sociológico}

Série II

$37 \mid 2020$

Número 37

\title{
Arte(s) Urbana(s), Ricardo Campos e Sílvia Câmara, V.N.Famalicão : Húmus, 2020. ISBN : 9789897554582, $194 \mathrm{pp}$
}

\section{Clara Sarmento}

\section{(2) OpenEdition}

Journals

Edição electrónica

URL: https://journals.openedition.org/sociologico/9582

DOI: $10.4000 /$ sociologico.9582

ISSN: 2182-7427

Editora

CICS.NOVA - Centro Interdisciplinar de Ciências Sociais da Universidade Nova de Lisboa

Edição impressa

Paginação: 63-65

ISSN: 0872-8380

Refêrencia eletrónica

Clara Sarmento, «Arte(s) Urbana(s), Ricardo Campos e Sílvia Câmara, V.N.Famalicão : Húmus, 2020.

ISBN : 9789897554582, 194 pp», Forum Sociológico [Online], 37 | 2020, posto online no dia 23

dezembro 2020, consultado o 31 março 2022. URL: http://journals.openedition.org/sociologico/9582 ; DOI: https://doi.org/10.4000/sociologico.9582 


\title{
Arte(s) Urbana(s), Ricardo Campos e Sílvia Câmara, V. N. Famalicão: Húmus, 2020. ISBN: 9789897554582. 194 pp.
}

\author{
Clara Sarmento \\ Centro de Estudos Interculturais (CEI), ISCAP-P. PORTO, Portugal
}

Na contracapa de Arte(s) Urbana(s), os autores Ricardo Campos e Sílvia Câmara apresentam-nos a obra com a seguinte sinopse:

\begin{abstract}
A arte urbana corresponde a um movimento artístico que, não sendo propriamente novo, tem tido uma crescente visibilidade desde o início do milénio. A arte urbana converteu-se gradualmente num elemento familiar, marcando a paisagem da cidade contemporânea. Está presente em muros, fachadas, postes, calçadas, mobiliário urbano ou transportes, adaptando-se ao meio envolvente. Proveniente de uma linhagem antiga de manifestações pictóricas presentes no espaço público urbano, este fenómeno corresponde a uma grande família de técnicas e expressões plásticas e merece, decididamente, a atenção da academia. E, na verdade, tem despertado a atenção de investigadores de áreas científicas muito diversas, sendo debatida a partir do olhar da arquitectura, da geografia, dos estudos urbanos, da história da arte, da sociologia, da antropologia, entre outras disciplinas.
\end{abstract}

Aqui se anunciam as três principais linhas de orientação desta obra de grande qualidade e agradável leitura, que responde não só às exigências do público especializado, mas também ao interesse crescente do público em geral: a arte urbana enquanto marca indelével dos territórios urbanos contemporâneos; a conceptualização e evolução diacrónica desta forma de arte; a sua interacção paradoxal com instituições públicas, privadas e académicas. Desta complexidade advém o carácter plural das Arte(s) Urbana(s) anunciadas no título.

O Prefácio e o Posfácio são opções astutas por serem da autoria dos reconhecidos artistas Alexandre Farto, aka Vhils, e Miguel Januário, aka MaisMenos, respectivamente. Mas estes não se limitam a deixar uma marca de visibilidade em Arte(s) Urbana(s). Bem pelo contrário, constroem textos profundos, estabelecendo uma ligação afectiva e analítica entre a prática artística e a prática académica, como artistas/académicos que também eles são. Alexandre Farto começa por evocar os murais políticos da sua infância e a street art perseguida pelas autoridades, em face da publicidade invasiva, "polida e formatada", socialmente aceite porque ao serviço do capital, do consumo e da disseminação de representações simplistas, aka estereótipos. Vhils associa as "vinhetas coloridas nas ruas" a um "gesto humano e anónimo", a uma dádiva generosa do artista à cidade, fazendo recordar os artistas anónimos das catedrais medievais. Vhils parte da atracção ou da repulsa irracionais e emotivas que a arte no espaço público desperta para logo mostrar que está ciente do quão necessária é "a participação democrática num espaço que deveria ser verdadeiramente público". Como só raramente o é, Vhils sabe que a arte urbana traça um percurso político que "ajuda a tornar visível o invisível" ( $p$. 11). O Prefácio de Vhils inclui ainda uma definição precisa e muito abrangente de "arte urbana" (p. 9), só possível a quem escreve à luz de um saber de experiência feito. Do mesmo saber comunga Miguel Januário, que, no Posfácio, também se mostra ciente da vastidão do neologismo que dá título ao livro, bem como da "linguagem de contrabalanço da supremacia capitalista das cidades" (p. 190) que é o graffiti, estabelecendo ainda um interessante paralelismo cronológico entre a emergência dos murais de Abril e o nascimento do graffiti nos Estados Unidos. De novo emerge no Posfácio de MaisMenos a reflexão sobre os paradoxos de uma arte outrora pública e, agora, cada vez mais privatizada, símbolo da mercantilização das contraculturas marginais (p. 191) e da tendencial aceleração das culturas imagéticas ( $p$. 188), que a internet faz correr à velocidade da luz. MaisMenos encerra o livro com uma nota positiva, igualmente política, ao afirmar que a crescente passividade da(s) arte(s) urbana(s) assimiladas está ainda a tempo de converter-se em "potencial crítico e transformativo" da sociedade (p. 192).

Miguel Januário escreve que Ricardo Campos e Sílvia Câmara cumprem com esta obra um trabalho que se volve missão de criação e comunicação de ciência. Esta é, sem dúvida, a definição perfeita do percurso dos autores, do qual nasceu $\operatorname{Arte}(s)$ Urbana(s). O livro encontra-se organizado em 
duas partes: a primeira, "Artes na Cidade", define, problematiza e desenvolve conceitos como graffiti, street art, pós-graffiti, arte pública e espaço público; a segunda, "Arte Urbana no Contexto Nacional", apresenta casos de referência internacionais e nacionais, com especial (demasiada...) incidência em Lisboa - o que prejudica a actualidade e o alcance do livro -, encerrando com o levantamento de alguns (insuficientes) projectos noutras regiões do país.

A Introdução retoma o mote da arte urbana contemporânea, enquanto alternativa democrática e participativa que problematiza o museu e a galeria, além de ser factor essencial ao dinamismo da vida metropolitana, evidente em cidades como Lisboa, São Paulo, Londres, Berlim ou Filadélfia ( $p$. 15). E Porto, Aveiro, Águeda, Jacarta, Hong Kong, Istambul, acrescentaríamos nós, a bem da evolução do paradigma geográfico da arte urbana. Campos e Câmara prosseguem com o carácter político, subversivo e essencialmente livre da comunicação através da arte urbana, à semelhança da internet ou do sistema alternativo de comunicação W.A.S.T.E. de The Crying of Lot 49 de Thomas Pynchon. A arte urbana que se ficcionalizou n'O Francoatirador Paciente de Arturo Pérez-Reverte e se canonizou com Keith Haring e Jean-Michel Basquiat é "usada e abusada pelos media" (p. 17) nas suas peças (des)informativas, bem como pela publicidade, moda e turismo, e "minada por preconceitos" de violência e misoginia que, infelizmente, ainda subalternizam as muitas artistas que brilham na cena inter/nacional. E não será decerto a opção por murais exclusivos para criadoras, como aquele que integra o projecto "Rostos do Muro Azul" (p. 155), que vai demolir o ghetto onde o machismo tenta encerrar as artistas, dentro do ghetto mais lato onde a sociedade tenta encerrar a arte urbana.

A polissemia da(s) arte(s) urbana(s) revela-se também na interdisciplinaridade inclusiva do debate que suscita - à semelhança da ágora grega, oportunamente evocada a propósito da definição de arte pública (p. 37) - e nas muitas semióticas e interculturalidades que a sustentam. A cidade é assim personificada como falante, metaforizada enquanto discurso e metonimizada como espaço de comunicação polifónico (p. 28). E, paradoxalmente, tanta da marginalidade associada ao graffiti decorre do secretismo da actividade, do mutismo dos autores, da sua linguagem impenetrável e imprevista (p. 74). Também paradoxal será a desmaterialização da arte urbana - por definição forjada no mais concreto dos materiais: a cidade -, ao tornar-se bem de consumo global através da internet, que é estrategicamente utilizada por inúmeros autores graças à visibilidade que proporciona (p. 77).

O carácter dissidente e político das contraculturas urbanas é amplamente descrito, convocando momentos tão distintos como o hip-hop, o Maio de
68, o punk, os hippies, a queda do Muro de Berlim, a Primavera Árabe e o movimento Occupy, num trajecto pendular entre a arte e a política que espelha o poder político da arte (ver Estética e Política: $A$ Partilha do Sensível, de Jacques Ranciére, justamente referido na p. 53). Mas o poder da arte que inscreve a estética - e até a ética - na cidade ( $p .47)$ é anónimo, volátil, livre e, por isso mesmo, ameaçador para as hegemonias. Daí nasce a obsessão destas pela censura, sob a forma de acções de limpeza urbana, de imposição da parede branca e inócua, da mesma forma que, nas décadas de 50 e 60 do século $X X$, censuraram e higienizaram a arte móvel e anónima do barco moliceiro. A política artística dos poderes autoritários é sempre de algum modo "privada" porque impede o posicionamento livre do cidadão em face da arte (p. 51). A arte privada privilegiará o sagrado monumental, ao passo que a arte pública se exprime no quotidiano profano, para empregar a categorização de Émile Durkheim. Por isso, não se compreende a hesitação que os autores terão tido em incluir numa obra sobre arte urbana uma secção dedicada ao mural político (p. 79), pois o "muralismo e o graffiti políticos" cumprem uma função tão cívica quanto o "muralismo comunitário" (p. 93). Ambos dão voz e poder simbólico aos oprimidos, seja pelos muros da Cisjordânia, pelas arbitrariedades da troika e seus acólitos, ou pelo esquecimento - também ele opressivo - do Estado, dos poderes locais e da sociedade conformada em geral. As imagens escolhidas para ilustrar esta secção (em boa hora incluída) testemunham todo o poder dessa simbologia, que Ricardo Campos já explorara exemplarmente no capítulo "The Crisis on the Wall: Political Muralism and Street Art in Lisbon", em Crisis, Austerity, and Transformation: How Disciplinary Neoliberalism Is Changing Portugal (ed. Isabel David, Lexington Books, 2018).

"Street art e pós-graffiti" (p. 95) oferece uma das secções mais vivas e desafiantes de $\operatorname{Arte}(s)$ Urbana(s), ao questionar a simultânea elitização e massificação do graffiti, que só aparentemente constrói novo paradoxo, bem como a transição do graffiti ilegal para o graffiti artístico, a "artificação" de Shapiro e a metamorfose dos vândalos perseguidos em artistas consagrados. A reflexão erudita dos autores culmina numa bem organizada "definição provisória da 'Arte Urbana'" em nove pontos (p. 108), em que, entre muitas outras, se destaca a passagem "a arte urbana não comunica apenas através do conteúdo gráfico e expressivo das suas obras, mas também através de toda a performatividade inerente ao gesto transgressivo" (p. 112).

A segunda parte de $\operatorname{Arte}(s)$ Urbana(s), "Arte Urbana no Contexto Nacional", parece enfermar do lugar-comum tão anedótico quanto trágico que confunde o país com a capital. Os "Alguns casos emblemáticos de cidades internacionais" (p. 120), 
nos quais se destaca a perspicaz observação dos ciclos e contraciclos de Barcelona ao sabor das ideologias políticas do momento, ocupam bem menos páginas do que as detalhadas descrições da "Política pública para a Arte Urbana em Lisboa" (p. 126) e da "Síntese historiográfica da arte urbana em Lisboa" (p. 140), que é também a secção mais e mais bem ilustrada de toda a obra. É com grande agrado que se (re)encontram aqui os grandes nomes da arte urbana nacional, que já fazem parte do quotidiano de inúmeras vilas e cidades portuguesas. Após uma primeira secção sem fronteiras, de reflexão literalmente global, a promessa dos exemplos internacionais peca por escassa e já algo clássica nos casos de Filadélfia e Berlim. Mas, estando cientes de que esta secção se intitula ser sobre o contexto nacional, ainda mais claustrofóbica se torna ao dividir-se, na realidade, entre Lisboa e "o resto", estando este confinado à secção "Alguns projectos nacionais de referência" (p. 163), com apenas 11 páginas. Os autores mostram-se cientes dos riscos de uma selecção pessoal e da dificuldade de elaborar um inventário completo. Contudo, este levantamento nem sequer "percorre transversalmente o território nacional" (p. 163). Fora da capital, apenas encontramos Covilhã, Porto (cuja vibrante cena de arte urbana não merece referência posterior a 2014), Lagos e Angra do Heroísmo, para logo se regressar a Cascais, Oeiras e Loures, concelhos que integram a Grande Lisboa. Há exemplos de boas práticas em intervenção artística e comunitária, em conservação e acervos digitais, em investigação e disseminação científica, por todo o território nacional, não esquecendo o Norte e o Centro, pois, se a(s) arte(s) urbana(s) são plurais, os seus territórios também o são.

A resposta às poucas lacunas apontadas ficará decerto para uma próxima edição, pois é óbvio que esta obra se tornará em breve numa referência incontornável para todos os estudiosos e apreciadores das artes urbanas, de futuro descodificadas sempre no plural, graças ao tão aguardado substrato teórico que Arte(s) Urbana(s) criou. Mais imagens, se possível a cores, mais diversas e actuais, bem como uma bibliografia ainda mais abrangente e que inclua na íntegra a extensa produção dos autores, serão melhorias muito apreciadas.

A Conclusão retoma a minuciosa reflexão crítica de secções anteriores e cumpre em pleno o objectivo de contribuir para "o debate (...) sobre o campo das intervenções visuais no espaço público urbano" ( $p$. 175). Recorda as ambiguidades e tensões não resolvidas - os tais paradoxos - que atravessam actualmente este campo, nomeadamente os contextos cada vez mais "seguros, vigiados e controlados de produção de obras de arte de rua em rápida transição para a galeria" (p. 177). Felizmente, existem hoje em dia projectos de investigação que conferem igual atenção à arte urbana legal-controlada-segura e à arte urbana ilegal-livre-perigosa (?), que conservam ambas em acervos digitais de acesso livre e que investigam os "conflitos em torno da remoção de obras das paredes (para destruição, venda ou simples preservação" (p. 178), como o projecto StreetArtCEI do Centro de Estudos Interculturais do Politécnico do Porto ou o projecto "O direito à cidade - Street art e lei" do Centro de Investigação Jurídico-Económica da Faculdade de Direito da Universidade do Porto. A investigação que está a ser realizada em todo o país é garantia de que o trabalho aqui publicado faz já parte de um diálogo a muitas vozes que "irá ser central nos próximos anos", como afirmam Campos e Câmara no derradeiro parágrafo de $\operatorname{Arte}(s)$ Urbana(s).

Esta obra está licenciada com uma Licença Creative Commons Atribuição - 4.0 (CC BY 4.0).

Recebido a 18/09/2019. Aceite para publicação a 09/10/2020

Clara Sarmento. Centro de Estudos Interculturais (CEI), ISCAP-P.PORTO, Portugal. Email: clarasarmento@gmail.com 